There will also be apparatus for the production of chemical smoke, as well as an amplifier and a loud speaker installation permitting lectures or music, which will be broadcast during the displays. According to the Electrician of May 21, all the services of the Government broadcasting system will be transferred to the radio pavilion at the Paris Exhibition. For this purpose, three large studios with mixing desks and control room, two smaller studios for speakers and announcers, and a television studio are being installed. There will also be an installation for the registering and rebroadcasting of records. The installations will be entirely enclosed in glass so that the public can see all the equipment in operation and yet all risk of noise or crowds interfering with the operations will be prevented. As the stations are broadcasting all day, it will be possible for the public to see at least some part of the inctallation in operation at all hours of the day. The lighting tour has been organized to extend until the end of October. The general control of the whole system will be centred in a room near the entrance to the pavilion. It will have connexions with both French and foreign stations. In many places, the local authorities are being asked to provide flood-lighting for other buildings of interest.

\section{Modern Applications of Psychology}

Dr. C. S. MYers, in a paper before the Royal Society of Arts on March 10 on "Industrial Psycho. logy and the Modern World", began by showing the indebtedness of this most recent application of psychology to the educational and medical applications that had preceded it. The field covered by it is very wide, since it is concerned with all grades of occupational life, with industrial relations, personnel management and with all the environmental con. ditions that can hinder or further the happiness, health and efficiency of those engaged in industry. Already the pioneer work done in England is being developed and adapted by many other countries. By a scientific study of individual differences and of the requirements for success in particular occupations, the industrial psychologist has been able to develop a technique which enables him to direct an entrant into the occupation for which he seems most fitted, and also to help the employer to select from a number of applicants those with the fundamental requirements. The young person is thereby saved from much futile groping and the attendant sense of failure. When, however, the right selection has been made, it becomes necessary to train the beginner in the right methods, instead of letting him pick up for himself methods that might be good or might be bad. In this field, the industrial psychologist has made a special study of the best movements and methods of work that should be taught, and of the suitable methods of teaching the required movements. $\mathrm{He}$ has also much to offer to management, and could prevent the unnecessary friction resulting from those in authority having more knowledge of the machinery and of the materials involved than of the human beings for whom they are responsible.

\section{British Speleological Society}

Althougr the British Spelleological Society has been in existence for a brief period only, having been formed at Derby two years ago, there is evidence that the organization has fulfilled its purpose and indeed has prospered exceedingly under the presidency of Sir Arthur Keith in the announcement that it proposes to institute a museum of its own. The object of the Society is to co-ordinate the exploration and excavation of caves and potholes, and as was evident from the very successful first conference held at Buxton last year, much useful work on these lines has already been done. The Society now proposes to take over Cragdale, Settle, as its headquarters, and a museum will be formed to house photographs of underworld scenery, geological specimens, human and animal remains as well as other relics of cave man. A speleological library will also be formed and housed in the new headquarters. The second Speleological Conference and exhibition of photographs, surveys, prehistoric remains, geological specimens, etc., from British and foreign caves will be held in the University of Bristol on July 23-26. Further information can be obtained from the deputy secretary of the British Speleological Association, University College, Hull. On July 27-August 8, there will be a conducted tour to some of the more important caves in Germany, Austria and Czechoslovakia. Further information can be obtained from Mr. C. R. Hewer, Tallin, Kiriku Poik 4, Estonia.

\section{Charles Darwin and the Modern Theory of Tropisms}

Prof. Boysen Jensen's new book upon "Growth Hormones in Plants" directs attention to the conclusion drawn by Charles Darwin "that when seedlings are freely exposed to a lateral light, some influence is transmitted from the upper to the lower part, causing the latter to bend". Prof. N. Cholodny writes to the Editor from Kiev pointing out that a passage from "The Power of Movement in Plants" (1880) refers to the localization of phototropic sensibility in the tip of the coleoptile of Phalaris in these terms : "These results seem to imply the presence of some matter in the upper part which is acted on by light, and which transmits its effects to the lower part". Prof. Cholodny points out that this passage might be interpreted as foreshadowing modern theoretical interpretations of the same tropic phenomenon as due to the movement of growth-1 egulating substances or hormones.

\section{Health Resorts of Britain and the Empire}

The British Health Resorts Association has issued its official handbook for the current year ("British Health Resorts: Spa, Seaside, Inland". Edited by Dr. R. Fortescue Fox. With a Foreword by Sir Kingsley Wood, Minister of Health. London : J. and A. Churchill, Ltd. $2 s .6 d$. net). The handbook follows the lines of previous editions, but the whole of the material has been carefully revised, and new information is given in a condensed form as regards the sunshine and rainfall in many resorts. A valuable chapter on climatology has been contributed by 
Mr. L. C. W. Bonacina. A synopsis of the attractions offered by British resorts during the 'invalid's winter' is included, and the principal spas and climatic resorts of the British Commonwealth overseas are also mentioned.

\section{Fauna of the North Sea}

LIEF. 30 of "Die Tierwelt der Nord- und Ostsee" contains a mixed bag of monographs, dealing with nemertine worms (Hermann Friedrich), halophile and halobionic Hemiptera (Hakon Lindberg), and the Anthozoa included in the sea anemones and Alcyonaria (F. Pax). Short diagnoses of the characters of species and of their distribution are supplemented by accounts of the morphology, physiology, development, variation and biology in general of larger groups. Parts of this ambitious and very useful work have been appearing at the rate of slightly less than three a year since 1925, and there are still many to follow.

\section{A Forestry Herbarium}

THE forestry herbarium collected by the late Prof. A. H. Henry, formerly professor of forestry at University College, Dublin, has now been made available for inspection and reference at the Botanic Gardens, Glasnevin, Dublin. The collection comprises more than nine thousand specimens and was presented to the nation by Mrs. Henry on the death of her husband. Since then, Mrs. Henry has devoted much time to the work of classification and arrangement so as to make the collection readily accessible for reference purposes. This unique collection is a tribute to the memory of a distinguished scholar, and the admirable arrangement accomplished by Mrs. Henry enhances that tribute.

\section{The Cerne Giant: A Correction}

It would appear that the announcement of the impending sale of the Cerne Giant (see Nature, May 22, p. 876) was due to a misunderstanding. The sale of Cerne Abbas property, which will take place on June 16, will include the remains of the famous Abbey and an Elizabethan farm-house; but the well-known hill 'carving' is not for sale. The Cerne Giant, we are reminded by the secretary of the National Trust, was presented to the National Trust in 1920 by Mr. A. E. Fox Pitt-Rivers and an endowment provided for its upkeep by Sir Henry Hoare.

\section{The Night Sky in June}

ON June 21 at $20^{\mathrm{h}}$, the sun enters the sign Cancer (the summer solstice). In the latitude of London, the length of night from sunset to sunrise is then only $7^{\mathrm{h}} 26^{\mathrm{m}}$. The moon is new on June $8^{\mathrm{d}} 20 \cdot 7^{\mathrm{h}}$ and full on June $23^{\mathrm{d}} 23 \cdot 0^{\mathrm{h}}$. On June 8 , a total eclipse of the sun takes place and is visible in equatorial regions of the Pacific, but although the path of totality (of maximum breadth 153 miles) extends over nearly one hundred degrees of terrestrial longitude, there are very few possible land sites to which expeditions can be sent. The duration of totality at the noon point is $7^{\mathrm{m}} 4^{\mathrm{s}}$, making this eclipse the longest that has occurred for more than a thousand years. Of the planets visible during June, both Mercury and Venus are morning stars. On June 6, Mercury is at greatest elongation $24^{\circ}$ west, and Venus at greatest western elongation $\left(46^{\circ}\right)$ on June 27 . Venus is in conjunction with Uranus on June 18 at $11^{\mathrm{h}}$, when the two planets are separated by $2 \cdot 7^{\circ}$. Mars is conspicuous low in the south as the sky darkens. The planet decreases in brightness from magnitude $-1 \cdot 7$ to $-1 \cdot 2$ during the month. On June 20 at $\mathrm{K}^{\mathrm{h}}$, Mars is in conjunction with the moon and is then only $0 \cdot \mathrm{I}^{\circ}$ northwards of the latter (geocentric positions). The circumstances produce an occultation of Mars by the moon, the phenomenon not, however, being visible from the northern hemisphere. Jupiter rises in the evening twilight and souths about $2^{\mathrm{h}}$ in the middle of the month ; on June 25 at $21^{\mathrm{h}}$ it is in conjunction with the moon. Saturn rises soon after midnight in mid-June ; on June 4 at $2^{\mathrm{h}}$ conjunction occurs with the moon. The apparent breadth of the minor axis of the ring system is $3^{\prime \prime}-4^{\prime \prime}$. At $22^{\mathrm{h}}$ in mid-June, the bright star Regulus is nearing the western horizon; Arcturus has passed the meridian, Sr ica and Antares are low down in the south, while Vega, Altair and Deneb are conspicuous eastwards of the meridian. The maximum of the Scorpiid meteors is due about June 4, the radiant point being nearly midway between $\propto$ Scorpii (Antares) and $\eta$ Ophiuchi. An ephemeris for the comet Grigg-Skjellerup, is given in the B.A.A. Handbook as follows:

\begin{tabular}{|c|c|c|}
\hline & R.A. & Dec. (N.) \\
\hline Juṇe 4 & $9^{\mathrm{h}} \quad 36 \cdot 3^{\mathrm{m}}$ & $23^{\circ} \quad 36^{\prime}$ \\
\hline , 8 & $10 \quad 04 \cdot 5$ & $25 \quad 53$ \\
\hline , 12 & $1036 \cdot 0$ & $28 \quad 02$ \\
\hline " 16 & $11 \quad 10 \cdot 3$ & 2951 \\
\hline, 20 & $1146 \cdot 8$ & $31 \quad 10$ \\
\hline, 28 & $13 \quad 01 \cdot 2$ & 3150 \\
\hline
\end{tabular}

\section{Commonwealth Fund Fellowships}

THE following appointments, among others, to Commonwealth Fund fellowships tenable by British graduates in American universities for the two years beginning September, 1937, have been made: Dr. J. B. Bateman, King's College, London, and University of Cambridge, to the University of Pennsylvania, in biophysics; D. M. Douglas, University of St. Andrews, to the University of Minnesota, in medicine ; J. A. Downes, Imperial College of Science and Technology, London, to the University of California, in zoology; Dr. R. N. Jones, University of Manchester, to Harvard University, in chemistry ; N. F. McGrath, University College, Oxford, to the University of Chicago, in political science; Wilfred Merchant, Corpus Christi College, Oxford, to the Massa. chusetts Institute of Technology, in engineering; Dr. Arthur Porter, University of Manchester, to the Massachusetts Institute of Technology, in physics; H. O. Puls, University of Reading, to the Massa. chusetts Institute of Technology, in physics; Dr. F. D. Richardson, University College, London, to Princeton University, in chemistry; Dr. B. V. Rollin, Wadham College, Oxford, to the University of California, in physics ; J. D. Spillane, University 